\title{
Adaptabilidade de carreira: Paradigmas do conceito no mundo do trabalho contemporâneo
} Career adaptability:

Paradigms of the concept in the contemporary world of work Adaptabilidad de carrera: Paradigmas del concepto en el mundo del trabajo contemporáneo

Milena Carolina FIORINI ${ }^{1}$

Marucia Patta BARDAGI

Narbal SILVA

Universidade Federal de Santa Catarina, Florianopólis, SC, Brasil

Resumo

Este artigo analisa as perspectivas epistemológicas, teóricas e metodológicas referentes ao conceito de adaptabilidade de carreira, dentro de um quadro evolutivo no campo da psicologia organizacional e do trabalho, e mais especificamente na área de aconselhamento de carreira (career counseling). O esquema de quadrantes epistemológicos sugeridos por Burrel e Morgan (1979) foi utilizado como referência para identificar as mudanças paradigmáticas que o construto adaptabilidade de carreira foi assumindo, desde sua elaboração na década de 1980, até o momento. Pretende-se, ainda, apresentar a importância da adaptabilidade de carreira no mundo do trabalho contemporâneo, bem como o caráter dinâmico e multifacetado que os estudos e a prática em aconselhamento de carreira têm adotado em relação ao conceito, tanto no que diz respeito aos aspectos paradigmáticos quanto metodológicos.

Palavras-chave:

Adaptabilidade de carreira; paradigma; aconselhamento.

\section{Abstract}

This article analyzes the epistemological, theoretical, and methodological perspectives for the concept of career adaptability within an evolutionary framework in the field of organizational and work psychology, and more specifically in the area of career counseling. The epistemological quadrants scheme suggested by Burrell and Morgan (1979) was used as reference to identify the paradigmatic changes that the career adaptability construct was assuming, since its elaboration in the ' $80 \mathrm{~s}$ until the present. The article also aims to present the importance of career adaptability in the contemporary world of work, as well as the multifaceted and dynamic aspects that various studies and career counseling practice have adopted regarding the concept, from both approaches - paradigmatic and methodological.

Keywords:

Career adaptability; paradigm; counseling.

Resumen Este artículo analiza las perspectivas epistemológicas, teóricas y metodológicas referentes al concepto de adaptabilidad de carrera, dentro de un cuadro evolutivo en el campo de la psicología organizacional y del trabajo, y más específicamente en el área de orientación profesional. El esquema de cuadrantes epistemológicos sugeridos por Burrel y Morgan (1979) ha sido utilizado como referencia para identificar los cambios paradigmáticos que el constructo adaptabilidad de carrera fue asumiendo, desde su elaboración, en la década de 80 , hasta el momento actual. Se pretende, además, mostrar la importancia de la adaptabilidad de carrera en el mundo del trabajo contemporáneo, bien como el carácter dinámico y multifacético que los estudios y la práctica en orientación profesional han adoptado en relación con el concepto, tanto con respecto a los aspectos metodológicos como a los paradigmáticos.

Palabras-clave:

Adaptabilidad de carrera; paradigma; orientación profesional.

Endereço para correspondência: Universidade Federal de Santa Catarina, Departamento de Psicologia, Centro de Filosofia e Ciências Humanas, Sala 14르, Trindade, Florianópolis, SC, Brasil 88040-970. Email: milena_fiorini@yahoo.com.br 
$\mathrm{O}$ s cientistas sociais partem de pressupostos que orientam a construção e a fundamentação de suas teorias (Burrell \& Morgan, 1979), explicitamente ou de forma implícita. Esses pressupostos dizem respeito à escolha de uma posição epistemológica coerente com determinada visão sobre a natureza do conhecimento. A epistemologia é, portanto, um ramo da filosofia que estuda a investigação científica e seu produto: o conhecimento científico (Bunge, 1973). Na Psicologia, o surgimento de um conhecimento de caráter científico ocorreu entre o final do século XIX e início do século XX, caracterizado pela diversidade e divergência de abordagens dos fenômenos psicológicos (Filho \& Martins, 2007). Da mesma forma, a história da psicologia organizacional e do trabalho foi demarcada pela multidisciplinaridade e variedade de orientações teórico-metodológicas, ao dialogar com vários campos de conhecimento (Leão, 2012).

O campo da orientação profissional, no âmbito da psicologia organizacional e do trabalho, desenvolveu-se vinculado à seleção de pessoas e centrado na modalidade estatística (Melo-Silva, Lassance, \& Soares, 2004). Nasceu como uma prática ligada diretamente ao aumento da eficiência industrial, com o objetivo de detectar trabalhadores aptos a desenvolver determinadas atividades (Sparta, 2003). A orientação profissional estruturou-se no início do século XX, a partir de teorias e práticas baseadas em epistemologias diversas, desenvolvidas principalmente nos Estados Unidos, posteriormente na Europa e, por fim, espalhou-se pelo mundo (Ribeiro, 2013). Tanto sua origem quanto sua evolução vêm, portanto, acompanhando as mudanças que ocorreram gradativamente na forma de gerir os sujeitos no contexto organizacional (Duarte, 2006).

A partir do século XXI, o desenvolvimento da orientação profissional passou a enfrentar uma série de desafios, que culminaram, inclusive, no emprego contemporâneo de um novo termo, o aconselhamento de carreira (career counseling), mais condizente com a concepção atual da temática, que será explorada posteriormente. $\mathrm{O}$ processo de globalização e o avanço da tecnologia contribuíram para a imprevisibilidade da carreira, exigindo dos trabalhadores o desenvolvimento de competências substancialmente diferentes daquelas requeridas pelas profissões do século XX. Como apontam Savickas et al. (2009), "os trabalhadores precários da era da informação deverão tornar-se aprendizes permanentes, capazes de utilizar tecnologias sofisticadas, assumir a flexibilidade ao invés da estabilidade, manter a sua empregabilidade e criar as suas próprias oportunidades" (p. 393).

Diante da multiplicidade de visões teóricas evidenciadas pela trajetória da ciência psicológica, especialmente na área organizacional e do trabalho, Burrell e Morgan (1979) buscaram relacionar as teorias de organização com seus contextos sociológicos mais amplos, propondo um quadro epistemológico referencial. Os autores sugeriram uma divisão entre as visões sobre a natureza da ciência social em quatro paradigmas: funcionalismo, interpretativismo, humanismo radical e estruturalismo radical.

\section{Os quatro paradigmas propostos por Burrell e Morgan}

Burrell e Morgan (1979), ao conceberem um quadro paradigmático referencial para o estudo das organizações, alegam que todos os cientistas partem de pressupostos explícitos ou implícitos a respeito da natureza do mundo social e da forma como ele pode ser investigado. Primeiramente, existem pressupostos de natureza ontológica, que se relacionam à essência do fenômeno a ser pesquisado; em segundo lugar, é necessário considerar as premissas de natureza epistemológica, que refletem a base de entendimento e a transmissão de conhecimento sobre o mundo social. Há, ainda, um conjunto de pressupostos relativos à concepção de natureza humana, representado pela relação entre os seres humanos e seu ambiente. Por fim, a associação entre ontologia, epistemologia e natureza humana impacta em questões de caráter metodológico, ou seja, no modo como se investiga o conhecimento.

Os autores dividem, ainda, a ontologia em nominalista e realista. No nominalismo, reside a crença de que a realidade é criada pela consciência do sujeito e representada por conceitos que tentam objetivá-la. Já no realismo predomina a ideia de que o mundo real existe independentemente da consciência. Os autores também propõem uma decomposição da epistemologia nos extremos positivista e antipositivista. O positivismo caracteriza-se pela busca de regularidades e relações causais para predizer a realidade social. Para o antipositivismo, o mundo social só pode ser compreendido sob a perspectiva do sujeito, que é participante do ambiente. As visões sobre a natureza humana são classificadas como deterministas ou voluntaristas. Por meio da concepção determinista, considera-se que o sujeito é condicionado pelo seu ambiente. A partir do voluntarismo, o entendimento preponderante é de que o sujeito é autônomo e exerce papel ativo no ambiente. 
O conjunto formado pela congruência entre as questões ontológicas, epistemológicas e de natureza humana possibilitam a escolha por determinada metodologia. Com base no realismo, no positivismo e no determinismo, a abordagem nomotética enfatiza a sistematização e a formulação de hipóteses. Apoiada pelas concepções nominalistas, antipositivistas e voluntaristas, a abordagem ideográfica compreende a ciência social como essencialmente subjetiva.

Para compreender de forma completa os fundamentos preconizados por Burrell e Morgan (1979), é preciso considerar também suas premissas sobre a natureza da sociedade, em termos de teorias que defendem a sociologia da regulação, em contraponto àquelas que adotam a sociologia da mudança radical. A primeira refere-se às abordagens que se preocupam em manter a ordem, a estabilidade, a integração e a funcionalidade. Seu foco é compreender por que a sociedade é mantida como uma entidade. Já a segunda é caracterizada como visionária, uma vez que o status quo é questionado. Busca descobrir explicações para uma mudança radical na sociedade e seu interesse é a emancipação do ser humano, por meio de conflito, coerção e desintegração. A partir desse conjunto de classificações, Burrell e Morgan (1979) desenvolveram um quadro referencial com quatro paradigmas distintos: funcionalismo, interpretativismo, humanismo radical e estruturalismo radical.

O funcionalismo é considerado o paradigma dominante no estudo das organizações (Burrell \& Morgan, 1979). Ao sustentar-se na sociologia da regulação, aborda o ser humano de um ponto de vista objetivista. Tende a ser realista, positivista, determinista e utilizar abordagens nomotéticas. O paradigma funcionalista é essencialmente pragmático, orientado para a solução de problemas, residindo a crença na existência concreta da realidade e na ordenação social, independente dos sujeitos que a observam. Para o funcionalismo, em conformidade com uma postura positivista, o conhecimento deve ser neutro, objetivo e isento de qualquer juízo de valor. Seus métodos de pesquisa, portanto, recusam o envolvimento do pesquisador com o objeto de pesquisa (Minayo, 2013).

O paradigma interpretativista também se ajusta à sociologia da regulação, porém com foco na compreensão da natureza social por meio da experiência subjetiva. Contudo, inversamente ao funcionalismo, é nominalista, antipositivista e voluntarista. Utiliza metodologias ideográficas e considera o pesquisador como participante da ação, e não como um simples observador (Vergara \& Caldas, 2005). Para o interpretativismo, a realidade social só adquire existência a partir da visão do sujeito, sendo o mundo social compartilhado intersubjetivamente por meio de significados.

O humanismo radical define-se pelo interesse na sociologia da mudança radical a partir de críticas ao status quo, de uma perspectiva subjetivista. Baseia-se nas premissas nominalistas, antipositivistas, voluntaristas e ideográficas. Na concepção do paradigma humanista radical, a consciência do homem é dominada por superestruturas ideológicas que geram a alienação, sendo que a preocupação dessa corrente é libertar o sujeito das restrições impostas pelos arranjos sociais.

Já os teóricos do estruturalismo radical concordam com os humanistas radicais em relação à sociologia da mudança radical, porém defendem um ponto de vista objetivista. Segundo Burrell e Morgan (1979), da mesma forma que o funcionalismo, o paradigma estruturalista radical baseia-se na visão realista, positivista, determinista e nomotética. No entanto, diferencia-se do paradigma funcionalista, ao conceber que a emancipação do homem é possibilitada por meio de conflitos, mudanças estruturais e crises políticas e econômicas.

No modelo epistemológico postulado por Burrell e Morgan (1979), entre outros aspectos, é retratado um dilema entre a objetividade e a subjetividade das abordagens que influenciaram a construção da psicologia das organizações e do trabalho. Ao considerar a orientação profissional, a perspectiva objetivista e positivista da realidade social, marcada pela predição e pelo controle, foi predominante até os anos 1960. A partir da década de 1970, a carreira passou a ser concebida sob um enfoque mais psicossocial e relacional (Taveira, 2000).

Da década de 1990 em diante, as abordagens em orientação profissional passaram a evidenciar mais substancialmente as influências históricas e contextuais (Ribeiro, 2011). As mudanças socioeconômicas, acentuadas gradativamente por todo o mundo, afetaram grandes setores da população, gerando problemas como desemprego, falta de qualidade de vida no trabalho e transições da escola para a vida profissional (Duarte, 2013). As crises econômicas, reestruturações e demissões da sociedade pós-industrial não garantem mais uma carreira ordenada e sequencial, sendo que tanto jovens quanto adultos precisam lidar com transições frequentes de trabalho (Nota, Ginevra, \& Soresi, 2012). Uma resposta importante diante desse cenário é a adaptabilidade de carreira, definida como a habilidade para lidar adequadamente com as tarefas de desenvolvimento, 
preparando-se para exercer o papel de trabalhador e mostrando-se capaz de lidar com as mudanças no mercado e nas condições de trabalho (Nota et al., 2012; Savickas, 2005).

A área de conhecimento em psicologia organizacional e do trabalho tem como objetivo compreender a maneira como interagem os diversos aspectos que integram a vida das pessoas, dos grupos e das organizações, propondo formas de preservar, promover e reestabelecer a qualidade de vida e o bem-estar das pessoas, mesmo em meio a constantes transformações (Zanelli \& Bastos, 2004). Quando se analisa a relação entre trajetória de carreira e contexto organizacional, a adaptabilidade de carreira assume grande relevância. À medida que as demandas de gestão e planejamento organizacional se alteram em uma velocidade cada vez maior, buscando atender às constantes reconfigurações do mundo do trabalho, os profissionais, em geral, também são desafiados a adotar uma postura adaptativa e flexível, a fim de agregarem valor por meio de sua atuação, e, como consequência, manterem a sua empregabilidade.

A concepção inicial de adaptabilidade de carreira foi elaborada por Super e Knasel (1981) sob um ponto de vista mais objetivista, seguindo as ideias da teoria desenvolvimentista. Savickas $(2005,2013)$ passou gradualmente a compreender a carreira e a adaptabilidade como construções subjetivas, formadas por significações de memórias passadas, experiências atuais e expectativas futuras de carreira (Ambiel, 2014). Percebe-se, portanto, que o conceito de adaptabilidade de carreira, dentro desse contexto de mudanças na área de orientação profissional e de diferentes influências epistemológicas, também assumiu perspectivas diversificadas.

Ao considerar os argumentos até aqui apresentados, neste artigo são propostos três objetivos: (a) relacionar o desenvolvimento das concepções epistemológicas e metodológicas adotadas pela produção científica sobre adaptabilidade de carreira com o quadro referencial sugerido por Burrell e Morgan (1979); (b) discutir a temática que envolve o construto adaptabilidade de carreira, ressaltando a importância progressiva que o termo vem apresentando no delineamento do conhecimento científico e da prática em orientação profissional; e (c) analisar as mudanças paradigmáticas que acompanharam as transformações referentes à concepção de adaptabilidade de carreira, bem como a pluralidade de abordagens metodológicas adotadas pelos estudos contemporâneos relativos ao tema.

\section{MÉTODO}

A coleta de dados para este estudo envolveu uma pesquisa bibliográfica realizada em livros e artigos científicos. Como parâmetros para a busca, foram utilizados nomes de autores referenciais em relação aos temas: orientação profissional/aconselhamento de carreira; historicidade e paradigmas referentes à carreira; e adaptabilidade de carreira. Os dados foram analisados inicialmente a partir do esquema de quadrantes proposto por Burrell e Morgan (1979), com o objetivo de estabelecer relações entre a evolução histórica da concepção de adaptabilidade de carreira e seus principais aspectos epistemológicos, teóricos, e metodológicos.

Com a finalidade específica de ilustrar o crescente aumento da produção científica em relação ao conceito de adaptabilidade de carreira, bem como a importância que o construto tem assumido no contexto de trabalho contemporâneo, foi realizada uma busca nas plataformas Web Of Science, Scopus, SciELO e PePSIC. Nas plataformas internacionais (Web of Science e Scopus), utilizou-se a palavra-chave career adapatability. Optou-se pelas áreas ciências sociais (Social Sciences) na Web of Science e ciências humanas e sociais (Social Sciences E Humanities) na Scopus. Nas plataformas nacionais (SciELO e PePSIC), a busca foi realizada com o emprego conjunto das palavras carreira e adaptabilidade. Em ambos os casos, não houve restrição de data na procura pelos artigos científicos. Como se trata de um artigo teórico, os dados referentes à revisão da literatura foram utilizados apenas com propósitos descritivos.

\section{Adaptabilidade de carreira: Conceito, historicidade e paradigmas}

As primeiras abordagens ligadas à orientação profissional tinham como foco adequar as características pessoais às necessidades de desempenho em atividades industriais (Oliveira, Guimarães, \& Dela-Coleta, 2006; Taveira, 2000). O modelo de traço e fator, orientado principalmente por testes de inteligência, aptidões, habilidades, interesses e personalidade vocacionais, predominou até a década de 1950 (Sparta, 2003). Posteriormente, surgiram as teorias psicodinâmicas, que buscavam explicar a escolha vocacional por meio de impulsos e motivações inconscientes, centrando-se na preocupação com a dinâmica interna do sujeito. A abordagem desenvolvimentista teve seu início com Eli Ginzberg (Sparta, 2003), inaugurando uma visão menos 
diretiva da prática de orientação profissional, ao propor que a escolha profissional é um processo evolutivo que inicia no final da infância e termina no início da vida adulta.

Dentro do foco desenvolvimentista, Donald Super (1980) delimitou uma mudança importante no estudo sobre a carreira, conceituando-a como uma sequência de posições ou papéis que uma pessoa desempenha ao longo de todo o ciclo de vida. Super elaborou e sistematizou diversos conceitos, como: estágios de desenvolvimento, autoconceitos, papéis de vida, maturidade de carreira e adaptabilidade de carreira (Balbinotti, 2003; Oliveira, Melo-Silva, \& Dela-Coleta, 2012) e sua produção científica enfatizou os conceitos de ajustamento e maturidade de carreira. Por meio de processos de ajustamento, o individuo é capaz de adaptar-se a diferentes situações para alcançar seus objetivos profissionais. A maturidade de carreira, por sua vez, é definida pelo autor como um conjunto de comportamentos e atitudes empregados pelo indivíduo, visando a sua inserção no mundo profissional.

A concepção de maturidade de carreira aplicava-se ao desenvolvimento vocacional especialmente na adolescência e início da vida adulta (Balbinotti, 2003). No entanto, ao conceber que a escolha profissional é um processo contínuo na vida do sujeito, Super e Knasel (1981) consideraram o conceito insuficiente para a avaliação de questões profissionais em adultos. Tendo em vista as possíveis situações diversas e imprevisíveis com as quais o sujeito pode ser confrontado durante todos os estágios do desenvolvimento vocacional, os autores passaram a empregar o conceito de adaptabilidade de carreira (Ambiel, 2014).

A compreensão dos diversos aspectos característicos da adaptabilidade de carreira teve uma progressão no decorrer dos estudos em orientação profissional, demonstrando a preocupação dos pesquisadores em aperfeiçoá-lo, de acordo com as demandas do mundo do trabalho. O modelo de adaptabilidade elaborado por Super, Thompson e Lindeman (1988) era composto de cinco dimensões: duas afetivas (disposição para planejar e exploração) e três cognitivas (informação, tomada de decisão e orientação para a realidade). Savickas (2011) reestruturou o conceito, dividindo-o em quatro dimensões: preocupação, controle, curiosidade e confiança. A preocupação refere-se à orientação positiva ao futuro da carreira; o controle relaciona-se à capacidade de controlar as tentativas de preparação para o futuro profissional; a curiosidade denota a habilidade para explorar possíveis cenários futuros de carreira; e a confiança diz respeito à disposição para implementar os planos profissionais (Savickas 2011; Savickas \& Porfeli 2012). Posteriormente, o autor aprimora a definição, conceituando-a como um processo psicossocial que denota a prontidão e os recursos do sujeito para lidar com tarefas atuais e iminentes de desenvolvimento de carreira, transições ocupacionais e traumas pessoais (Savickas, 2013).

Durante a última década, as consequências da globalização, da internacionalização e do avanço tecnológico têm tornado o mundo do trabalho mais flexível e imprevisível. A necessidade de adaptação a esse novo contexto vem atribuindo uma importância crescente ao estudo da adaptabilidade de carreira. Com o objetivo de operacionalizar o conceito, tornando-o uma ferramenta condizente com as circunstâncias socioeconômicas, um grupo de psicólogos vocacionais de 18 países formou o International Career Adaptability Project, responsável pela elaboração da Escala de Adaptabilidade de Carreira (Career Adapt-Abilities Scale - CAAS) (Savickas \& Porfeli, 2012).

Ao compreender a síntese da trajetória referente aos estudos relacionados à adaptabilidade de carreira, é possível concluir que o construto já possui definições constitutivas e operacionais bem delimitadas. Considerando que a sua primeira definição ocorreu na década de 1980, percebe-se que houve um avanço significativo em relação ao seu aprimoramento. A forma clássica de conceber a orientação profissional, baseada em um foco objetivista, foi construída nos cenários da Europa e dos Estados Unidos. Durante quase todo o século XX, as condições socioeconômicas estáveis no continente europeu e nos Estados Unidos possibilitavam uma trajetória de carreira previsível, contínua e dentro da normalidade (Ribeiro, 2013). Já o contexto da América Latina sempre apresentou uma realidade diferente, com condições socioeconômicas menos favoráveis e, portanto, instáveis. Porém, nas últimas décadas, os pesquisadores europeus e norte-americanos também têm sentido a necessidade de responder a demandas sociais e de trabalho dentro de uma conjuntura socioeconômica em transição (Ribeiro, 2013). Nos Estados Unidos, na última década, apenas 40\% dos trabalhadores estavam formalmente empregados e os outros $60 \%$ ocupavam postos de trabalho terceirizados e de curto prazo (Savickas, 2008).

Nota et al. (2012) relatam, a partir de dados provenientes da Comissão Europeia de 2011, que 60\% dos jovens tinham empregos com contratos de curto prazo. Ainda segundo Nota, Ginevra, Santilli e Soresi (2014), a crise econômica tem prejudicado gravemente a perspectiva de emprego dos jovens em países ocidentais. Os 
mesmos autores também trazem informações apresentadas pela Organização Internacional do Trabalho em 2013, que demonstram um aumento de 16,3\% na taxa de desemprego dos Estados Unidos e de 11\% nos países da Europa.

Com a progressiva heterogeneização, flexibilização e complexificação que atinge todo o mundo do trabalho, a ruptura do emprego passou a representar o modelo hegemônico de inserção no trabalho, gerando grandes mudanças de concepção, estrutura e desenvolvimento da carreira (Ribeiro, 2009). Todas essas transformações exigem o desenvolvimento de novas competências, atualização contínua de conhecimento e criação das próprias oportunidades profissionais (Nota et al., 2014). Dentre as competências requeridas pelo mundo do trabalho contemporâneo, a adaptabilidade de carreira merece destaque, justamente pelo seu caráter constitutivo, que prevê habilidades de adaptação tanto a situações profissionais cotidianas quanto imprevisíveis.

Com base nessa reflexão, será realizada uma contextualização das nuances que o conceito foi assumindo na teoria e na prática do aconselhamento de carreira. Além disso, pretende-se situar os paradigmas que os estudos sobre a adaptabilidade de carreira foram adotando, dentro do quadro referencial paradigmático construído por Burrell e Morgan (1979).

$\mathrm{Na}$ década de 1940, quando Super começou a desenvolver suas pesquisas, a concepção de carreira era associada exclusivamente às organizações, em um mundo estruturado pelo modelo taylorista-fordista, demarcado pelas influências da administração científica e da psicometria (Ribeiro, 2009). No cenário da época, ter uma carreira significava predefinir uma trajetória de trabalho em determinada organização, adaptando-se às suas condições. A definição de adaptabilidade de carreira ainda não havia sido concebida naquele momento. Porém, Super elaborou o conceito de maturidade da carreira, precursor do que viria a ser a adaptabilidade. Ao realizar uma análise epistemológica da visão de carreira e da concepção de maturidade dentro do contexto da metade do século XX, com base no quadro referencial proposto por Burrell e Morgan (1979), percebe-se sua congruência com um paradigma essencialmente funcionalista, caracterizado pelo positivismo. Ribeiro (2009) concorda, ao afirmar que o modelo desenvolvimentista "introduz a ideia da carreira como uma construção psicossocial por meio da visão funcionalista, sendo a concepção de perfil trocada pela de desenvolvimento e a psicologia vocacional pela psicologia vocacional evolutiva, sendo seu principal autor Donald Super” (p. 205).

As primeiras formulações da abordagem desenvolvimentista de Super especificavam os comportamentos profissionais como característicos e previsíveis a cada fase específica de desenvolvimento (Oliveira et al., 2012). Essa visão é coerente com a crença em uma realidade concreta e determinista, enraizada na ontologia realista. Além disso, nas premissas da teoria desenvolvimentista, havia uma concordância com a manutenção da realidade social, da forma como se apresentava. Em relação à questão metodológica, os postulados iniciais da abordagem eram compatíveis com a escolha de métodos nomotéticos. Como exemplo, cita-se a primeira tentativa de elaboração de um instrumento para avaliação da maturidade de carreira, o Career Maturity Inventory (CMI), na década de 1970 (Ambiel, 2014). Ressalta-se, ainda, que a própria teoria de Super é resultado direto de observações empíricas, frutos de um estudo longitudinal iniciado em 1951, que acompanhou a trajetória de carreira de sujeitos com idades entre 14 e 15 anos até os seus 25 anos (Bardagi, 2010).

Cabe ressaltar que, até meados da década de 1970, os paradigmas relacionados à carreira apresentavam certa dicotomia entre desenvolvimento vocacional e planos organizacionais de carreira, caracterizando um problema epistemológico crônico, tendo em vista a pluralidade de enfoques (Ribeiro, 2009). Diante dessa dicotomia, a teoria de desenvolvimento de carreira de Super passou por vários refinamentos ao longo de seus sessenta anos de trabalho, incluindo os segmentos diferencialista, desenvolvimentista, fenomenológico e contextual (Oliveira et al., 2012). Entre o final da década de 1970 até a década de 1990, Super, junto a outros pesquisadores, aperfeiçoou sua teoria, incluindo algumas dimensões contextuais em suas premissas desenvolvimentistas. Nesse momento, o autor inseriu uma análise psicossocial ao âmbito da carreira, em resposta às primeiras sinalizações de demandas instáveis e flexíveis do trabalho. A abordagem desenvolvimentista passou a substituir concepções de continuidade para um olhar mais processual, advertindo que as dimensões contextuais e as características individuais não permitiam um percurso tão linear quanto a idade cronológica (Bardagi, 2010).

Em 1979, Super e Knasel realizaram uma releitura do conceito de maturidade de carreira, que resultou na criação do termo adaptabilidade de carreira. Savickas (1997) foi responsável por aprimorar gradativamente o conceito, idealizado a partir de uma definição geral de adaptabilidade, designada como a habilidade de adequar-se a mudanças e ajustar-se a novas circunstâncias. O nascimento do conceito de adaptabilidade dentro da abordagem desenvolvimentista começou a delimitar uma mudança gradual de um paradigma funcionalista 
para uma compreensão interpretativista. No entanto, embora Super (1990) e Savickas (1997) tenham implementado modificações importantes em relação aos seus pressupostos teóricos, ainda predominava uma visão mais positivista em relação à carreira e à adaptabilidade.

Savickas (2005), ao dar continuidade às ideias de Super, elaborou a teoria de construção da carreira (Career Construction Theory $-C C$ ). A grande mudança dessa perspectiva foi a busca de uma compreensão referente ao processo interpretativo e interpessoal pelo qual os sujeitos constroem sentidos e direcionam seu comportamento vocacional (Oliveira et al., 2012). A teoria de construção da carreira foi alicerçada pelos pressupostos da psicologia do desenvolvimento e pelo cognitivismo, porém, ao longo de seu desenvolvimento, passou a assumir um caráter construtivista (Ribeiro, 2011). Savickas $(2001,2005)$ passou, dessa forma, a tratar o desenvolvimento e a adaptabilidade de carreira sob um ponto de vista mais interpretativo, considerando que o sujeito constrói representações da realidade, sendo que a carreira é constituída à medida que ele realiza suas escolhas e expressa seus autoconceitos e objetivos. Savickas (2011) considera que o sujeito é adaptável em relação à sua carreira quando demonstra preocupação a respeito de seu futuro como trabalhador, ampliação do controle pessoal sobre o futuro de sua carreira, curiosidade para explorar possíveis cenários futuros e confiança na busca de suas aspirações vocacionais. Essa concepção fundamentou a elaboração da Escala de Adaptabilidade de Carreira (Career Adapt-Abilities Scale - CAAS) (Savickas \& Porfeli, 2012), iniciada em 2008 e concluída em 2012.

A internacionalização progressiva do aconselhamento de carreira levou os especialistas ao redor do mundo a rever conjuntamente suas teorias e técnicas (Savickas et al., 2009). Pesquisadores de sete países (Bélgica, França, Itália, Portugal, Suiça, Holanda e Estados Unidos) compuseram o Life Designing International Research Group, com o objetivo de facilitar o intercâmbio, adaptar modelos e técnicas e aperfeiçoar o conhecimento científico em relação ao desenvolvimento de carreira (Ambiel, 2014; Savickas et al., 2009). O grupo propôs uma nova abordagem para a orientação profissional do século XXI: a teoria de construção da vida (Life Designing). O modelo Life Designing tem como base teórica o construcionismo social e como referência epistemológica o interpretativismo. A noção de carreira, para a perspectiva construcionsista, evidencia um movimento que atribui significados às memórias do passado, às experiências do presente e às aspirações para o futuro, reunindo-as a fim de constituírem um tema de vida (Duarte, 2009).

O construcionismo fundamenta-se na ideia de que a realidade não é um dado natural e predeterminado, mas é construída em uma relação psicossocial, por meio da prática do discurso social. O mundo social não se trata, portanto, de uma verdade objetiva, e sim de discursos que se produzem e se compartilham acerca da realidade. Do ponto de vista epistemológico, a crença essencial é a de que o conhecimento é histórico e cultural, sendo a linguagem muito mais do que uma simples representação dos fatos sociais (Ribeiro, 2009). A orientação profissional, ao ser tratada de um ponto de vista construcionista, adota uma ontologia relativista, assumindo que a realidade é construída socialmente por meio dos discursos sociais; uma epistemologia intersubjetivista, na medida em que acredita na construção do conhecimento por meio de discursos sobre a realidade e não na realidade em si mesma; e uma metodologia dialógica e transformadora, sendo que a realidade é construída e negociada pelas relações psicossociais (Ribeiro, 2011).

É possível perceber que os paradigmas sobre carreira e orientação profissional foram sendo modificados progressivamente, até se chegar ao conceito de "aconselhamento de carreira". Essas transformações ocorreram em consonância com as necessidades delimitadas pelas mudanças no mundo do trabalho e pelo consequente aumento de exigências em relação aos trabalhadores e aos próprios conselheiros de carreira. Tendo como base o quadro referencial de Burrell e Morgan (1979), pode-se inferir que o conceito contemporâneo de carreira adota um paradigma interpretativista da realidade social, à medida que seu entendimento concebe a natureza social como uma experiência subjetiva. Seus pressupostos apoiam-se na ontologia nominalista e na epistemologia antipositivista, sendo que, para o modelo Life Designing, o conhecimento do sujeito e a construção de sua identidade são resultados de um contexto de interações e negociações entre pessoas e grupos.

A abordagem Life Designing defende que a carreira é apenas um dos aspectos da vida das pessoas, propondo que o processo de aconselhamento de carreira deve auxiliá-las a lidar com as questões oriundas da vida pós-moderna. Enfatiza a necessidade de construir projetos de carreira, antecipar e lidar com as transições profissionais e considerar a esperança de um futuro previsível (Savickas et al., 2009). A partir dessa nova perspectiva, a adaptabilidade de carreira passa a ser constituída por meio da relação entre um sujeito ativo e dinâmico frente a uma realidade de vida em constante mudança (Savickas \& Porfeli, 2012). 
A adaptabilidade desenvolve-se por meio da interação entre o mundo interno e externo. Portanto, a cultura e as condições do contexto influenciam significativamente o seu aprimoramento (Savickas \& Porfeli, 2012). Diferentes cenários socioeconômicos tendem a apresentar níveis distintos de promoção da capacidade de adaptabilidade de carreira, tendo em vista que fornecem oportunidades e recursos específicos. Dessa forma, acredita-se que as condições contemporâneas de incerteza que assolam também os Estados Unidos e a Europa, e não somente a América Latina, foram determinantes para uma construção mais consensual da forma de conceber a adaptabilidade de carreira, tanto nas pesquisas quanto na prática profissional.

Em relação à epistemologia, não é possível afirmar categoricamente que o construto adaptabilidade de carreira assumiu um caráter eminentemente interpretativista. Porém, é possível deduzir que, acompanhando a mudança paradigmática referente ao conceito de carreira, a adaptabilidade tem sido tratada sob ambos os paradigmas (funcionalista e interpretativista), dependendo, principalmente, do tipo de estudo proposto. $\mathrm{O}$ processo de elaboração da Escala de Adaptabilidade de Carreira descrito por Savickas e Porfeli (2012), por exemplo, foi desenvolvido a partir da contribuição de diversos olhares e culturas. Apesar de ter um caráter mais funcionalista, é evidente a preocupação dos autores em contextualizar o seu desenvolvimento, buscando integrar aspectos relacionais e contextuais.

Nesse sentido, concorda-se com Silveira e Hüning (2007), que apontam uma democratização dos valores epistemológicos. Os autores argumentam que existe uma tendência contemporânea das instâncias epistemológicas de produção do conhecimento, a deixarem de buscar seus fundamentos em uma instância superior, para reconhecerem na sua prática a capacidade para gerar a própria legitimidade. Esse ponto de vista permite deduzir que a perspectiva paradigmática atual referente à adaptabilidade de carreira é condizente com uma noção de fundamentação epistemológica distinta da clássica, porém legitimada a partir do aprimoramento de sua produção científica.

Conforme afirmam Burrell e Morgan (1979), a ontologia e a epistemologia são orientadoras para a escolha do método. Coerente com essa afirmação, as mudanças de paradigma que ocorreram na trajetória da orientação profissional também impactaram na utilização de determinados métodos. No início dos estudos sobre carreira, os métodos objetivavam colocar "o homem certo no lugar certo" (Oliveira et al., 2012). Os psicólogos do século XX, influenciados pelas ciências naturais, buscavam leis universais que dirigissem o comportamento humano, sendo que a pesquisa tinha como foco os traços de personalidade, utilizando-se de medidas objetivas e perfis normativos (Savickas et al., 2009). Dessa forma, as metodologias prevalecentes no século passado apresentavam uma concepção nomotética, coerente com o paradigma funcionalista.

Já a visão contemporânea de carreira, representada principalmente pelo modelo Life Designing, acredita que o uso exclusivo de mensurações objetivas é insuficiente para descrever os sujeitos. Alega que a identidade profissional é dinâmica e derivada das histórias de vida de cada um, sendo que o uso exclusivo de escores ou testes descreve perfis estáticos, abstratos e simplificados (Savickas et al., 2009). Em relação aos métodos utilizados para avaliar a adaptabilidade de carreira, Nota et al. (2014) argumentam que a antiga forma de investigação permitia comparar os escores de uma pessoa com dados normativos, traçando-se um perfil referente ao nível de adaptabilidade.

Atualmente, embora o método quantitativo, geralmente com utilização da escala de adaptabilidade de carreira, continue sendo uma ferramenta válida e importante, a abordagem Life Designing passou a incluir, também, métodos qualitativos, por meio de entrevistas, histórias de vida e narrativas. Nota et al. (2014) relatam que existe um número razoável de pesquisas tanto qualitativas quanto quantitativas para avaliar questões de adaptabilidade de carreira. Na construção conjunta da Escala de Adaptabilidade de Carreira (Savickas \& Porfeli, 2012), por exemplo, além dos procedimentos psicométricos, alguns países (Austrália, Inglaterra e África do Sul) também utilizaram métodos qualitativos nos processos de validação e adaptação. A partir de premissas construcionistas sociais, a abordagem qualitativa para avaliar a adaptabilidade de carreira pode integrar recursos como: entrevistas, genograma, cartas e lembranças (Nota et al., 2014). O uso das narrativas é um dos principais pilares da prática, sendo que, por meio das histórias, o sujeito é estimulado a desenvolver as quatro competências de adapatabilidade, identificando estratégicas para aprimorá-las, a partir de temas de sua própria vivência (Savickas, 2005).

Verifica-se, com base nessas reflexões, que as abordagens metodológicas contemporâneas no campo do aconselhamento de carreira, e mais especificamente em relação ao construto adaptabilidade de carreira, utilizam métodos nomotéticos e ideográficos, dentro do esquema de quadrantes sugerido por Burrell e Morgan 
(1979). Essa constatação é consoante com a reflexão sugerida anteriormente, que legitima uma compreensão epistemológica oscilante entre os paradigmas funcionalista e interpretativista, ao analisar a realidade social. $\mathrm{O}$ método nomotético é representado por investigações que utilizam a abordagem quantitativa, já o ideográfico caracteriza-se pelo emprego de procedimentos qualitativos. Em geral, essas opções metodológicas costumam ser colocadas em termos de oposição (Silveira \& Hüning, 2007). Frente a essa discussão, aceita-se a diretriz proposta por Minayo e Sanches (1993), ao afirmarem que os métodos qualitativos e quantitativos não são contraditórios, mas que apresentam, ao contrário, uma natureza diferente e complementar.

\section{A adaptabilidade de carreira no mundo do trabalho contemporâneo}

A crença de que a adaptabilidade de carreira é um recurso fundamental para enfrentar os desafios na construção da carreira (Nota et al., 2014) tem despertado o interesse pelo tema, fato que pode ser testemunhado pelo aumento do número de publicações científicas ao longo dos últimos anos, principalmente no âmbito internacional. Para ilustrar e corroborar essa informação, alguns dados encontrados por meio da busca em plataformas nacionais e internacionais podem ser observados na Tabela 1.

TABELA 1. Levantamento da produção científica sobre adaptabilidade de carreira*

\begin{tabular}{|c|c|c|c|c|c|c|}
\hline \multirow{3}{*}{ Ano de publicação } & \multicolumn{6}{|c|}{ Produção científica sobre adaptabilidade de carreira } \\
\hline & \multicolumn{3}{|c|}{ Plataformas internacionais } & \multicolumn{3}{|c|}{ Plataformas nacionais } \\
\hline & Web of Science & Scopus & $\begin{array}{c}\text { Total } \\
\text { (internacional) }\end{array}$ & SciELO & PePSIC & Total (nacional) \\
\hline 2015 & 20 & 19 & 39 & - & - & - \\
\hline 2014 & 21 & 22 & 43 & - & 1 & 1 \\
\hline 2013 & 16 & 19 & 35 & 1 & - & 1 \\
\hline 2012 & 18 & 20 & 38 & - & 2 & 2 \\
\hline 2011 & 6 & 6 & 12 & - & 1 & 1 \\
\hline 2010 & 9 & 8 & 17 & - & - & - \\
\hline 2009 & 3 & 3 & 6 & - & - & - \\
\hline 2008 & 3 & 2 & 5 & - & - & - \\
\hline 2007 & 1 & 2 & 3 & - & - & - \\
\hline 2006 & 1 & 1 & 2 & - & - & - \\
\hline 2005 & 5 & 4 & 9 & - & - & - \\
\hline 2004 & 1 & - & 1 & - & - & - \\
\hline 2002 & 3 & 1 & 4 & - & - & - \\
\hline 1997 & 3 & 2 & 5 & - & - & - \\
\hline 1996 & 1 & 1 & 2 & - & - & - \\
\hline 1995 & 2 & - & 2 & - & - & - \\
\hline 1994 & 1 & - & 1 & - & - & - \\
\hline Total por plataforma & 114 & 110 & 224 & 1 & 4 & 5 \\
\hline
\end{tabular}

Nota. *Busca realizada na data de 15 de julho de 2015.

Os dados apresentados na tabela permitem concluir que, especialmente nos últimos cinco anos, a produção científica que trata de temas relacionados à adaptabilidade de carreira teve um aumento significativo. Do total de 224 artigos internacionais, mais da metade (167) foram produzidos nesse período. Tratando-se dos artigos nacionais, a produção científica ainda é pequena, de apenas cinco artigos, todos desenvolvidos entre 2010 e 2015 .

A análise dessas informações denota uma reflexão acerca da grande diferença entre a quantidade de produção científica nacional e internacional. Acredita-se que essa disparidade é justificada, primeiramente, pelo fato de que a América Latina, em geral, importa abordagens e práticas dos Estados Unidos e da Europa (Ribeiro, 2013). Portanto, o investimento em conhecimento científico, a exemplo do Brasil, tende a ser posterior, ocorrendo, via de regra, quando o contexto internacional já possui uma bagagem de produção mais abrangente. Além disso, considera-se que o Brasil, dentro do cenário da América Latina, tenha se apropriado recentemente da concepção do construto adaptabilidade de carreira, devido, justamente, à mudança de concepção que foi adquirindo mundialmente. Com a formação do Life Design International Research Group (união de países que concebeu o modelo Life Designing) e do International Career Adaptability Project (conjunto de países que 
desenvolveu a Escala de Adaptabilidade de Carreira), a partir de 2008, a adaptabilidade de carreira passou a ser estudada de forma mais sistematizada, contemplando contextos socioeconômicos e culturais diversificados. Outro fator importante que pode explicar parte da diferença é a crise política, econômica e social atual, que vem acometendo também os Estados Unidos e a Europa. Esse fato tem gerado maior reconhecimento da importância da adaptabilidade de carreira frente às dificuldades que se agravam no mundo do trabalho como um todo.

O início dos estudos sobre adaptabilidade de carreira teve um foco maior no público entre final da adolescência e início da idade adulta, fase caracterizada, em geral, pelas decisões iniciais de carreira e pela transição da universidade para o mercado de trabalho. Porém, a crise econômica mundial, o consequente aumento das taxas de desemprego e a disseminação de trabalhos temporários ou informais têm gerado preocupação para um público cada vez maior. Todos esses fatores resultam na falta de perspectivas para adolescentes e jovens e na incerteza em relação à possibilidade de encontrar ou manter um emprego para pais de família.

A importância da adaptabilidade de carreira é, portanto, inegável diante dessa realidade, como um recurso para que as pessoas possam encontrar novas formas de pensar e planejar o seu futuro profissional (Nota et al., 2014). Um aspecto mais recente que vem conferindo também importância à adaptabilidade de carreira é a sua relação com o público de pessoas com deficiência. Nota et al. (2014) afirmam que mesmo para pessoas com algum tipo de deficiência, o trabalho pode desempenhar um papel essencial, à medida que proporciona $\mathrm{a}$ socialização e o desenvolvimento de uma autoimagem mais positiva.

É importante mencionar, ainda, que os ambientes de trabalho têm exigido um número cada vez maior de conhecimentos, habilidades e atitudes por parte dos trabalhadores, sem, no entanto, oferecer recompensas proporcionais em contrapartida. Isso tende a produzir efeitos negativos em relação à satisfação de vida das pessoas, além de possível diminuição do desempenho e problemas de saúde (Nota et al., 2014). Nesse sentido, a necessidade de ser flexível e manter o controle frente a situações de dificuldade profissional constituem fatores que exigem o aprimoramento da adaptabilidade de carreira.

\section{DISCUSSÃO}

As transformações no mundo do trabalho decorrentes da transição do século XX para o século XXI foram acompanhadas por mudanças na pesquisa no campo de aconselhamento de carreira. Algumas premissas mostraram-se determinantes para a formação do conhecimento científico na área de psicologia organizacional e do trabalho, dentre as quais se destaca o esquema de quadrantes paradigmáticos propostos por Burrell e Morgan (1979). Com base no quadro referencial sugerido pelos autores, é possível perceber que a concepção sobre carreira, inicialmente fundamentada em um paradigma substancialmente funcionalista, tem assumido um caráter cada vez mais interpretativista. Essa mudança gradativa de base epistemológica culminou em uma abordagem de orientação profissional que passou a compreender a carreira sob a perspectiva do construcionismo social.

No que se refere ao conceito de adaptabilidade de carreira, as considerações obtidas por meio deste estudo permitem suscitar reflexões e não, necessariamente, conclusões definitivas acerca do seu paradigma contemporâneo predominante. Os debates no campo da psicologia organizacional e do trabalho sempre foram influenciados por certa polarização entre objetividade e subjetividade ou positivismo e antipositivismo. Percebe-se que a concepção de adaptabilidade de carreira, assim como o conceito da própria carreira, tem seguido essa mesma linha, caracterizada por visões múltiplas e por vezes divergentes. Esse caráter multifacetado relativo aos paradigmas e às abordagens metodológicas que tratam do conceito de adaptabilidade de carreira é coerente com as necessidades atuais de pesquisas e intervenções em relação à temática. Estudos que investiguem o construto por meio de enfoques diversificados oportunizam um impacto mais expressivo e pertinente na prática de profissionais da área de psicologia organizacional e do trabalho.

O termo adaptabilidade de carreira, criado na década de 1980, ainda é relativamente novo, considerando a construção do conhecimento científico na área de aconselhamento de carreira. Além disso, vem sendo reformulado gradativamente, de acordo com a visibilidade dos autores diante das demandas provenientes dos desafios do mundo do trabalho. Portanto, defini-lo a partir de um paradigma único e definitivo talvez seja uma tentativa um tanto incipiente. Isso não denota menor importância às bases epistemológicas e ontológicas. Pelo contrário, acredita-se que é fundamental ter um referencial que apoie os pressupostos de teorias e o desenvolvimento de construtos. Entretanto, esse quadro de referência não pode ser estático, tendo em vista 
que a produção científica parte das demandas de uma realidade concreta, que é dinâmica e está em constante transformação.

Uma constatação significativa deste estudo diz respeito à importância cada vez mais evidente que a adaptabilidade de carreira tem adquirido no mundo do trabalho contemporâneo. Esse fato é comprovado pelo considerável aumento da produção científica, bem como pelas diversas nuances que o conceito tem assumido frente aos desafios da orientação profissional, eminentes tanto na América Latina quanto nos Estados Unidos e na Europa. É notória a necessidade de abarcar a adaptabilidade de carreira como um recurso fundamental por parte dos estudiosos e dos profissionais da área de psicologia organizacional e do trabalho, especialmente daqueles que atuam diretamente com aconselhamento de carreira. Frente às demandas de adequação à instabilidade e imprevisibilidade do mundo do trabalho que se manifestam em uma velocidade cada vez maior, futuramente a adaptabilidade de carreira tende a tornar-se uma competência imprescindível, tanto para os profissionais quanto para as organizações como um todo.

Por fim, a discussão suscitada referente às bases ontológicas, epistemológicas e metodológicas da adaptabilidade de carreira permite constatar que o construto tem grande potencial de exploração em múltiplos contextos e de formas variadas. Tendo em vista as concepções contemporâneas que vêm sendo atribuídas ao conceito, investigações no campo da adaptabilidade de carreira com pessoas com deficiência, por exemplo, seriam bastante válidos para o avanço no conhecimento científico. Outra temática pertinente poderia tratar da necessidade de desenvolvimento/aperfeiçoamento da adaptabilidade de carreira dos próprios conselheiros de carreira, diante das rápidas transformações no mundo do trabalho que o aconselhamento de carreira precisa abarcar.

\section{REFERÊNCIAS}

Ambiel, R. A. M. (2014). Adaptabilidade de carreira: Uma abordagem histórica de conceitos, modelos e teorias. Revista Brasileira de Orientação Profissional, 15(1), 15-24.

Balbinotti, M. A. A. (2003). A noção transcultural de maturidade vocacional na teoria de Donald Super. Psicologia: Reflexão e Crítica, 16(3), 561-473.

Bardagi, M. P. (2010). A abordagem cognitivo-evolutiva do desenvolvimento vocacional. In R. S. Levenfus \& D. H. S. Soares (Orgs.), Orientação vocacional ocupacional (pp. 227-243). Porto Alegre: Artmed.

Bunge, M. (1973). Philosophy of physics. Dordrecht: D. Reidel.

Burrell, G., \& Morgan, G. (1979). Sociological paradigms and organizational analysis. London: Heinemann Educational Books.

Duarte, M. E. (2006). Desenvolvimento e gestão de carreiras: Prelúdio e fugas (ou a psicologia da construção da vida). Revista Portuguesa de Psicologia, 39, 41-64.

Duarte, M. E. (2009). Um século depois de Frank Parsons: Escolher uma profissão ou apostar na psicologia da construção da vida? Revista Brasileira de Orientação Profissional, 10(2), 5-14.

Duarte, M. E. (2013). A vida da orientação na vida do século XXI: Constrangimentos e desafios. Revista Brasileira de Orientação Profissional, 14(2), 165-164.

Filho, K. P., \& Martins, S. (2007). A subjetividade como objeto da(s) psicologia(s). Psicologia \& Sociedade, 19(3), 14-19.

Leão, L. H. C. (2012). Psicologia do trabalho: Aspectos históricos, abordagens e desafios atuais. ECOS - Estudos Contemporâneos da Subjetividade, 2(2), 291-305.

Melo-Silva, L. L., Lassance, M. C. P., \& Soares, D. H. P. (2004). A orientação profissional no contexto da educação e trabalho. Revista Brasileira de Orientação Profissional, 5(2), 31-52.

Minayo, M. C. S.(2013). O desafio do conhecimento: Pesquisa qualitativa em saúde (13a ed). São Paulo: Hucitec.

Minayo, M. C., \& Sanches, O. (1993). Quantitativo-qualitativo: Oposição ou complementaridade? Caderno de Saúde Pública, 9(3), 239-262.

Nota, L., Ginevra, M. C., \& Soresi, S. (2012). The career and work adaptability questionnaire (CWAQ): A first contribution to its validation. Journal of Adolescence, 35(6), 1557-1569. doi: 10.1016/j.adolescence.2012.06.004

Nota, L., Ginevra, M. C., Santilli, S., \& Soresi, S. (2014). Contemporary career construction: The role of career adaptability. In M. Coetzee (Ed.), Psycho-social career meta-capacities: Dynamics of contemporary career development (pp. 247-263). Gauteng: Springer International Publishing Switzerland. 
Oliveira, M. C., Guimarães, V. F., \& Dela-Coleta, M. F.(2006). Modelo desenvolvimentista de avaliação e orientação de carreira proposto por Donald Super. Revista Brasileira de Orientação Profissional, 7(2), 11-18.

Oliveira, M. C., Melo-Silva, L. L., \& Dela-Coleta, M. F. (2012). Pressupostos teóricos de Super: Datados ou aplicáveis à psicologia vocacional contemporânea? Revista Brasileira de Orientação Profissional, 13(2), 223-234.

Ribeiro, M. A. (2009). A trajetória da carreira como construção teórico-prática e a proposta dialética da carreira psicossocial. Cadernos de Psicologia Social do Trabalho, 12(2), 203-216.

Ribeiro, M. A. (2011). Sexta demanda-chave para a orientação profissional: Como ajudar o indivíduo a construir dinamicamente sua carreira em um mundo em transição? In M. A. Ribeiro \& L. L. Melo-Silva (Orgs.), Compêndio de orientação profissional e de carreira: Enfoques teóricos contemporâneos e modelos de intervenção (pp. 15-51). São Paulo: Vetor.

Ribeiro, M. A. (2013). Reflexiones epistemológicas para la orientación profesional en América Latina: Una propuesta desde el construccionismo social. Revista Mexicana de Orientación Educativa, 10(24), 2-10.

Savickas, M. L. (1997). Adaptability: An integrative construct for life-span, life-space theory. The Career Development Quarterly, 45(3), 247-259. doi: 10.1002/j.2161-0045.1997.tb00469.x

Savickas, M. L. (2001). Developmental perspective on vocational behavior: Career patterns, salience and themes. International Journal for Educational and Vocational Guidance, 1, 49-57.

Savickas, M. L. (2002). Career construction: A developmental theory of vocational behavior. In S. D. Brown \& Associates (Eds.), Career choice and development (4a ed., pp. 149-205). San Francisco: Jossey Bass.

Savickas, M. L. (2005). The theory and practice of career construction. In S. D. Brown \& R. W. Lent (Eds.), Career development and counselling: Putting theory and research to work (pp. 42-70). Hoboken: Wiley.

Savickas, M. L. (2008). Helping people choose jobs: A history of the guidance profession. In R. Van Esbroeck \& J. A. Athanasou (Eds.), International handbook of career guidance (pp. 97-113). Dordrecht: Springer.

Savickas, M., Nota, L., Rossier, J., Dauwalder, J. P., Duarte, M. E., Guichard, J... van Vianen, A. E. M. (2009). Life designing: A paradigm for career construction in the 21st Century. Journal of Vocational Behavior, 75(3), 239-250. doi:10.1016/j. jvb.2009.04.004

Savickas, M. L. (2011). Career counseling. Washington, DC: American Psychological Association.

Savickas, M. L. (2013). The theory and practice of career construction. In S. D. Brown \& R. W. Lent (Eds.), Career development and counselling: Putting theory and research to work (2a ed., pp. 147-183). Hoboken: Wiley.

Savickas, M. L., \& Porfeli, E. J. (2012). Career adapt-abilities scale: Construction, reliability, and measurement equivalence across 13 countries. Journal of Vocational Behavior, 80, 661-673. doi: 10.1016/j.jvb.2012.01.012

Silveira, R. A. T., \& Hüning, S. M. (2007). A angústia epistemológica na psicologia. Psicologia: Teoria e Pesquisa, 23(4), 473-480. doi: 10.1590/S0102-37722007000400014

Sparta, M. (2003). O desenvolvimento da orientação profissional no Brasil. Revista Brasileira de Orientação Profissional, 4(1/2), $1-11$.

Super, D. E. (1980). A life-span, life-space approach to career development. Journal of Vocational Behavior, 16(3), 282-298. doi: 10.1016/0001-8791(80)90056-1

Super, D. E. (1981). A developmental theory: Implementing a self-concept. In D. H. Montross \& C. J. Shinkman (Eds.), Career development in the 1980s: Theory and practice (pp. 28-42). Springfield: Thomas.

Super, D. E., \& Knasel, E. G. (1981). Career development in adulthood: Some theoretical problems and a possible solution. British Journal of Guidance \& Counselling, 9, 194-201. doi: 10.1080/03069888108258214

Super, D. E. (1990). The life span, life space approach to career development. In D. Brown \& L. Brooks (Orgs.), Career choice and development, (2a ed., pp.197-261). San Francisco: Jossey-Bass.

Super, D. E., Thompson, A. S., \& Lindeman, R. H. (1988). Adult career concerns inventory: Manual for research and exploratory use in counseling. Palo Alto, CA: Consulting Psychologists Press.

Taveira, M. C. (2000). Exploração e desenvolvimento vocacional de jovens: Estudo sobre as relações entre a exploração, a identidade e a indecisão vocacional (Dissertação de mestrado). Recuperado de http://repositorium.sdum.uminho.pt/ handle/1822/19856

Vergara, S. C., \& Caldas, M. P. (2005). Paradigma interpretacionista: A busca da superação do objetivismo funcionalista nos anos 1980 e 1990. Revista de Administração de Empresas, 45(4), 66-72.

Zanelli, J. C., \& Bastos, A. V. B. (2004). Inserção profissional do psicólogo em organizações e no trabalho. In J. C. Zanelli, J. E. Borges-Andrade \& A. V. B. Bastos (Eds.), Psicologia, organizações e trabalho (pp. 466-491). Porto Alegre: Artes Médicas. 